\title{
Baroreceptor involvement in the immobility reflex of the frog: Evidence for a cross-species mechanism
}

\author{
DANIEL WEBSTER, THOMAS LANTHORN, DANIEL C. HATTON \\ and MARLE E. MEYER \\ University of Florida, Gainsville, Florida 32611
}

\begin{abstract}
Baroreceptor activity has been implicated in the initiation of the immobility reflex in rabbits (Hatton, Lanthorn, Webster, \& Meyer, 1978). In order to test the generality of the effect to other species, frogs, with the carotid labyrinth denervated or the glossopharyngeal nerve sectioned, were tested for the immobility reflex. The results indicate that sectioning of the glossopharyngeal nerve significantly reduced the incidence of immobility relative to controls, while frogs with the carotid labyrinth denervated were intermediate in susceptibility to immobility in comparison to sectioned and control animals.
\end{abstract}

The immobility reflex shares a number of common behavioral and physiological characteristics with the baroreceptor reflex. As pointed out by Gellhorn (1967), increased pressure in the sino-aortic area or stimulation of the sinus nerve leads to a fall in blood pressure and heart rate, a loss in tone of striated muscle, and a tendency to sleep. In addition, spindling occurs in the cortical EEG and there is a reduced responsiveness to external stimuli. These effects are not present after denervation of the sino-aortic area. Likewise, during the immobility reflex in rabbits, there is marked hypotension of the muscles (Carli, 1969) and an initial decrease in blood pressure and heart rate, followed by a rapid increase and gradual decrease in these values over the course of the immobility episode (Carli, 1974; Hatton, Note 1); there is also a reduced responsiveness to external stimuli, and synchronization occurs in the cortical EEG (Gerebtzoff, 1941; Hatton, Woodruff, \& Meyer, 1975). As with the baroreceptor reflex, the incidence of occurrence of immobility is significantly reduced in rabbits following denervation of the carotid sinus or sectioning of the sinus nerve (Hatton et al., 1978).

The present study was designed to examine the generality of the effect of denervation of the carotid sinus on the immobility reflex in another species.

\section{METHODS}

\section{Subjects}

The subjects were 30 Rana pipiens obtained from a commercial supplier. The frogs were housed as groups of three and four in 76-liter aquariums which contained approximately 5 liters

This research was supported by a Behavioral and Biomedical Science Research grant awarded to Merle E. Meyer. of water. Small pieces of wood were placed in the aquariums to allow the frogs a resting place. Lighting was an 8:16 light/dark cycle. Temperature was maintained at $20^{\circ} \mathrm{C} \pm 2^{\circ} \mathrm{C}$.

\section{Preoperative Procedure}

Each frog was subjected to an immobilization test session prior to surgery. The frog was transported from the aquarium to the testing room and placed in an upright position on a moist paper towel within an open-fronted plastic-covered plywood box. Immobility was induced $15 \mathrm{sec}$ later by rapidly inverting the frog and forcibly restraining it in the inverted position under the cupped hand of the experimenter. To prevent the frog's skin from adhering to the restraining hand when removed, latex examination gloves were worn when testing the animal.

After $10 \mathrm{sec}$ had elapsed, the hand was slowly withdrawn and a clock was started to time the duration of the response. If the frog did not become immobile within $10 \mathrm{sec}$, it was allowed to right itself and remain in the upright position for $15 \mathrm{sec}$ before another trial began. Three consecutive induction trials were given in this manner. An upper time limit of $10 \mathrm{~min}$ was imposed on the duration of the response. If the frog was still immobile after $10 \mathrm{~min}$, the trial was terminated by the experimenter.

\section{Operative Procedure}

Surgical anesthesia was induced by means of an injection of urethane at $2 \mathrm{mg} / \mathrm{g}$ IP. Following anesthesia, an incision was made horizontal to the body axis just anterior to the pectoral girdle. In 10 animals, the ninth cranial nerve was sectioned on either side of the bifurcation of the carotid artery. In an additional 10 animals, the carotid labyrinth and adjacent areas were denervated, using blunt dissection. The remaining 10 animals were used as controls. In the control operation, an incision was made and the underlying muscle tissue was parted but none of the nerves innervating the carotid laby rinth were damaged.

\section{Postoperative Testing}

Twenty-four hours postoperative, the animals were tested for immobility, utilizing the preoperative procedure described above. The frogs were given three trials for immobility on each of the 4 postoperative testing days. 
Table 1

Number of Trials, Out of $\mathbf{3 0}$, on Which Immobility Occurred

\begin{tabular}{|c|c|c|c|c|c|c|c|c|c|c|c|}
\hline \multicolumn{6}{|c|}{ Incidence of Immobility } & \multicolumn{6}{|c|}{ Chi-Square Values } \\
\hline & \multirow{2}{*}{$\begin{array}{l}\text { Preop- } \\
\text { erative }\end{array}$} & \multicolumn{4}{|c|}{ Postoperative } & & \multirow{2}{*}{$\begin{array}{l}\text { Preop- } \\
\text { erative }\end{array}$} & \multicolumn{4}{|c|}{ Postoperative } \\
\hline & & Day 1 & Day 2 & Day 3 & Day 4 & & & Day 1 & Day 2 & Day 3 & Day 4 \\
\hline Control & 19 & 22 & 20 & 17 & 18 & Overall & 1.38 & $10.32 *$ & $11.54^{*}$ & $11.55^{*}$ & $11.14^{*}$ \\
\hline Denervated & 18 & 14 & 15 & 10 & 16 & Sectioned vs. Control & & $9.64 *$ & $16.53 *$ & $9.49 *$ & $10.00 *$ \\
\hline \multirow[t]{2}{*}{ Sectioned } & 20 & 10 & 7 & 5 & 6 & Denervated vs. Control & & 4.44 & 1.71 & 3.30 & .27 \\
\hline & & & & & & Sectioned vs. Denervated & & 1.11 & $4.59 *$ & 2.22 & $7.17 *$ \\
\hline
\end{tabular}

Note-There were three trials per day for each animal, and 10 animals per group. The chi-square analyses were computed for each day's data separately. *Significant at .05 level.

\section{RESULTS}

The incidence of immobility for pre- and postoperative trials for the three groups are presented in Table 1 along with a summary table for the chi-square analysis of the data. As can be seen from Table 1, prior to surgical intervention, there were no significant differences among the groups $(p>.05)$. Following surgery, there were significant differences among the groups on each of the postoperative testing days $(\mathrm{p}<.05)$. Those animals with the ninth cranial nerve sectioned consistently showed significantly fewer incidences of immobility than control animals $(p<.05)$. Comparisons between the sectioned and denervated animals showed that the denervated animals had significantly more inductions of immobility on Days 2 and 4 than did the sectioned animals. With the exception of Day 1 postoperative, there were no significant differences between the control and denervated groups $(\mathrm{p}>.05)$.

There was no significant days effect in the data $[F(4,108)=1.86, p>.05]$. The ranking of the three groups was consistent on all postoperative days, with the sectioned group having the fewest number of inductions and the control groups having the greatest number.

\section{DISCUSSION}

The results show that, as in rabbits, sectioning of the ninth cranial nerve significantly lowers the susceptibility of frogs to the initiation of immobility. The lack of correspondence between the data for denervation of the carotid labyrinth and the sectioning of the glossopharyngeal suggests that either the labyrinth was not completely denervated or that the baroreceptors are not concentrated on the labyrinth as they are on the sinus of mammals.

The similarity of results between such divergent species as the frog and the rabbit suggests that involvement of baroreceptors may be common to a number of species that are susceptible to immobility despite considerable divergence in the anatomy of the arterial system.

Unlike the rabbit, the frog does not possess a carotid sinus but has a carotid labyrinth that is considerably more complex, anatomically. Nevertheless, it may be similar to the mammalian sinus in function (Adams, 1958). The innervation of the carotid sinus and the labyrinth appears to be similar in that the glossopharyngeal nerve and the vagal nerves are the two principle fiber tracts involved and depressor responses can be obtained through stimulation of the glossopharyngeal nerve (Adams, 1958). Presumably, the central projections from the glossopharyngeal and vagal nerves are similar in both species (Sarnat \& Netsky, 1974). In the cat, these projections are primarily to nucleus tractus solitarius and the medial medullary reticular formation, with secondary projections to the raphe nuclei (Miura \& Reiss, 1974). Since this area of the brainstem has been found to be involved in the immobility reflex in both rabbit and frog, it seems plausible that the neural circuitry underlying the response may be much the same (Carli, 1971; Klemm, 1969, 1971).

\section{REFERENCE NOTE}

1. Hatton, D. C. Unpublished observation.

\section{REFERENCES}

Adams, W. E. The comparative morphology of the carotid body and carotid sinus. Springfield, Ill: Thomas, 1958.

CARLI, G. Dissociation of electrocortical activity and somatic reflexes during rabbit hypnosis. Archives Italiennes de Biologie, 1969, 107, 219-234.

Carl, G. Subcortical mechanisms of rabbit hypnosis. Archives Italiennes de Biologie, 1971, 109, 15-26.

CARLI, G. Blood pressure and heart rate in the rabbit during animal hypnosis. Electroencephalography and Clinical Neurophysiology, 1974, 37, 231-237.

Gellhorn, E. Autonomic and somatic interactions. Minneapolis: University of Minnesota Press, 1967.

Gerebtzoff, M. A. État fonctionnel de l'écorce cérébrale au cours de l'hypnose animale. Archives Internationales de Physiologie et de Biochemie, 1941, 51, 365-378.

hatton, D. C.. Lanthorn, T., Webster, D., \& Meyer, M. E. Baroreceptor involvement in the immobility reflex. Behavioral Biology. 1978, 22. 122-127.

Hatton, D. C., Woodruff, M. L., d Meyer, M. E. Cholinergic modulation of tonic immobility in the rabbit (O) Mctolugus cuniculus). Journal of Comparative and Physiolesicul Psychology. 195: 89. 1053-106(). 
KLEMM, W. R. Mechanisms of the immobility reflex ("animal hypnosis"): II. EEG and multiple unit correlates in the brain stem. Communications in Behaviaral Biology, 1969, 3. 43-52.

KLEMM, W. R. Neurophysiologic studies of the immobility reflex ("animal hypnosis"). In S. Ehrenpresis \& O. C. Solnitzky (Eds.), Neuroscience research (Vol. 4). New York: Academic Press, 1971.
Miura, M.. d Reiss, D. J. Termination and secondary projections of carotid sinus nerve in the cat brain stem. American Journal of Physiology. 1974, 217, 142-153.

SARNAT, H. B., \& Netsky, M. G. Evolution of the nervous system. New York: Oxford University Press, 1974.

(Received for publication February 8, 1978; revision accepted May 26, 1978.) 